\title{
An Institutional Approach to Technology
}

\author{
Raymund Werle
}

The absence of general social theory in many Science, Technology \& Society (STS) studies seems to suggest that the specificity of the research object precludes a "conventional" approach to this area. In this article I introduce ActorCentered-Institutionalism (ACI), a variant of the institutionalist approach, to demonstrate the analytic power of (more or less) conventional social theory in the field of STS studies. ACI, I argue, is particularly well suited to linking the meso level and the micro level of analysis because it treats institutions and actors as equally important in the shaping of social processes and therefore also of technology as an element of these processes.

To highlight the assets of Actor-Centered-Institutionalism (ACI) this approach is contrasted with the Social Construction of Technology (SCOT) approach. Using empirical examples from the area of international technical standardization, I will show that ACI is not meant to replace SCOT but that either approach may benefit from the other. ${ }^{1}$

\section{Social Construction of Technology (SCOT)}

SCOT was introduced into technology research in 1984. In a programmatic paper, Trevor Pinch and Wiebe Bijker argue that the study of science and the study of technology should benefit from each other and that "the social constructivist view prevalent within the sociology of science, and which is also emerging in the sociology of technology, provides a useful starting point" (Pinch \& Bijker, 1984: 400). Analogous to the (at the time) well-established empirical program of relativism in the study of science, the SCOT approach focuses on the empirical study of the development of technology. Early on crucial principles and concepts of SCOT have been "interpretative flexibility", "closure and stabilization", and "relevant social groups". Wiebe Bijker has elaborated on these concepts and principles, and added further theoretical components in subsequent work (cf. Bijker, 1995a). I will come back to 
some of these components when I sketch the actor-centered institutionalist approach to explaining technical development.

In parallel to the SCOT approach, other variants of constructivist thinking have evolved in what is called the new sociology of technology (MacKenzie, 1990: 410; Winner, 1993: 367). "The turn to technology" (Woolgar, 1991) by sociologists of scientific knowledge, however, has largely remained a one-way street from science to technology rather than a give-and-take relation between two subdisciplines. This has found its most visible expression in both the concept of technology as text (Woolgar, 1987; 1991) and in the actor-network approach (e.g. Callon, 1987; Latour, 1987; 1992; Law \& Callon, 1992), which have also originated in the science studies domain. These approaches abandon $a$ priori distinctions between the technical and the social suggesting a general symmetry between the human and the nonhuman, which they claim to be able to analyze using the same conceptual framework. Most prominent has become Latour's notion of "actants" as a concept that encompasses - i.e., draws no distinction between - human actors and nonhuman entities. Granting agency to these entities in effect means rejecting distinctions which have been central to human-centered Western sociology (Collins \& Yearley, 1992). For sociologists in the Weberian tradition especially, it would, for instance, be unacceptable to treat technical artifacts as actors since they hold no values, intentions or beliefs.

This rather radical position, however, is only partly shared by the SCOT version of constructivism, which has also been influenced by the work of Tom Hughes, a historian of technology. Hughes has stressed the symbiotic relationship of technical and social elements in the development of large technical systems, forming what he calls a seamless web of heterogeneous elements (Hughes, 1986), but he in effect upholds a distinction between the obdurate material world and social phenomena such as human actors and organizations.

What have been the merits and shortcomings of social constructivism in the analysis of technology? Constructivism, first of all, has convincingly internalized technical development. It has made technological determinism obsolete. Technical change is no longer seen as autonomous or external to society, but as influenced and shaped by its societal context (cf. MacKenzie \& Wajcman, 1985). Technology is the dependent rather than the independent variable. Its development is no linear process where - following an inherent logic from the abstract to the concrete - scientists discover, engineers develop, manufacturers produce and users apply a technical artifact. Typically, as Langdon Winner (1993: 366, 367) has put it, "social constructivist interpretations of technology emphasize contingency and choice rather than forces of necessity in the history of technology". The undisputed methodological strength of constructivism lies in its case study approach. Case studies have facilitated opening the black box of technology and have illustrated social shaping processes.

In recent years, however, some discontent with the direction in which constructivism has developed has been expressed. The central focus of criticism is a lack of explanatory power on the part 
of constructivism. The reluctance of constructivists to draw analytical distinctions between the "social" and the "technical" is regarded as an ex ante exclusion of theories of social and institutional differentiation in the tradition of Max Weber and Talcott Parsons (cf. Bowden, 1995). Another flaw in the prevailing variants of constructivism is that the basic opposition against any form of technological determinism has lead to a social determinism, which is blind to the role of technical factors in the development of technology. The fact that this development is certainly underdetermined by technical factors does not allow to ignore these factors completely. Even if we regard technology as socially constructed, at a given point of time the technological "state-of-the-art" provides constraints and opportunities which are taken into consideration as if they were objective (cf. Vincenti, 1995). For a period of time they are invariant because nobody challenges them or they are protected through institutionalization. This is why technical development often appears to be path-dependent following specific technological trajectories (Arthur, 1989; Nelson \& Winter, 1977; 1982). In this sense a technological trajectory can be regarded as "an institutionalized form of technological change" (MacKenzie, 1990: 168).

Another line of criticism relates to the level of analysis of social constructivist studies. Analysts in the field of constructivism "are definitely micro oriented in their efforts to describe and explain technological innovation in terms of individual actions" (Sørensen \& Levold, 1992: 14). The micro view usually emphasizes the contingency of technical development and the variety of social factors linked to the individuals, who influence the development. This view tends to omit looking at the influence of the meso and macro level (Misa, 1994). The potential alternative to the micro view, the macro approach, also reveals deficiencies. Macro studies are inclined to technological determinism. They typically focus on the repercussions of technological change and at the same time level historical processes or conceive of them as largely independent of human awareness or micro influences. Therefore it has been suggested to direct attention to the meso level, to institutions intermediate between the individual and the state (Misa, 1994: 139). Such units include manufacturers organizations, consulting engineering firms, investment banking houses and standard-setting bodies but also social infrastructures such as competences, skills, and knowledge provided by universities, colleges and research institutes - not to mention the military, whose influence on science and technology has been significant (MacKenzie, 1990; Smit, 1995; Edwards, 1996; Norberg \& O’Neill, 1996). These meso-level phenomena are often used in institutionalist theorizing in political science and in economics to describe sectoral governance structures and innovation systems and to explain technical innovations (cf. Nelson \& Rosenberg, 1993; Etzkowitz \& Leydesdorff, 1997; Werle, 1997; Braczyk et al., 1998).

\section{Actor Centered Institutionalism (ACI)}

The theoretical emphasis on institutional aspects of technical development put forward at the end of the previous 
section opens up the prospect of integrating constructivist micro-level thinking into an institutional approach to explain technological development. This is facilitated by the actor-centered institutionalist approach which shall now be specified. ACI combines an institutional with an actor-related perspective (the meso level with the micro level). Institutions and actors jointly constitute the social setting which shapes technology. Being an approach rather than a theory actor centered institutionalism has the capacity to integrate social constructivism and link it to central theoretical components of institutional theory and actor theory. Integrating SCOT implies that the argument that technology is socially constructed has to be considered as the starting point and not the result of social theorizing about technology. In this sense, we can analyze how actors and institutions affect technical devel- opment if we use the ACI approach.

Technical development is a result of choices of individual and corporate actors. Technological choices can be explained as the outcome of the interactions of intentional actors. Institutions do not act intentionally or otherwise, neither do technical artifacts. They, however, channel, frame and contextualize action and interaction. The term actorcentered institutionalism is new (Mayntz \& Scharpf, 1995). Crucial conceptual elements of this approach are institutions, actors and actor constellations (Diagram 1), which I briefly outline drawing on a recent publication by Fritz Scharpf (1997).

Institutions are often regarded as equivalent with organizations. In ACI, however, the concept of institution is restricted to systems of rules that structure the courses of actions that a set of actors may choose. Rules include not

Diagram 1. Actor Centered Institutionalism

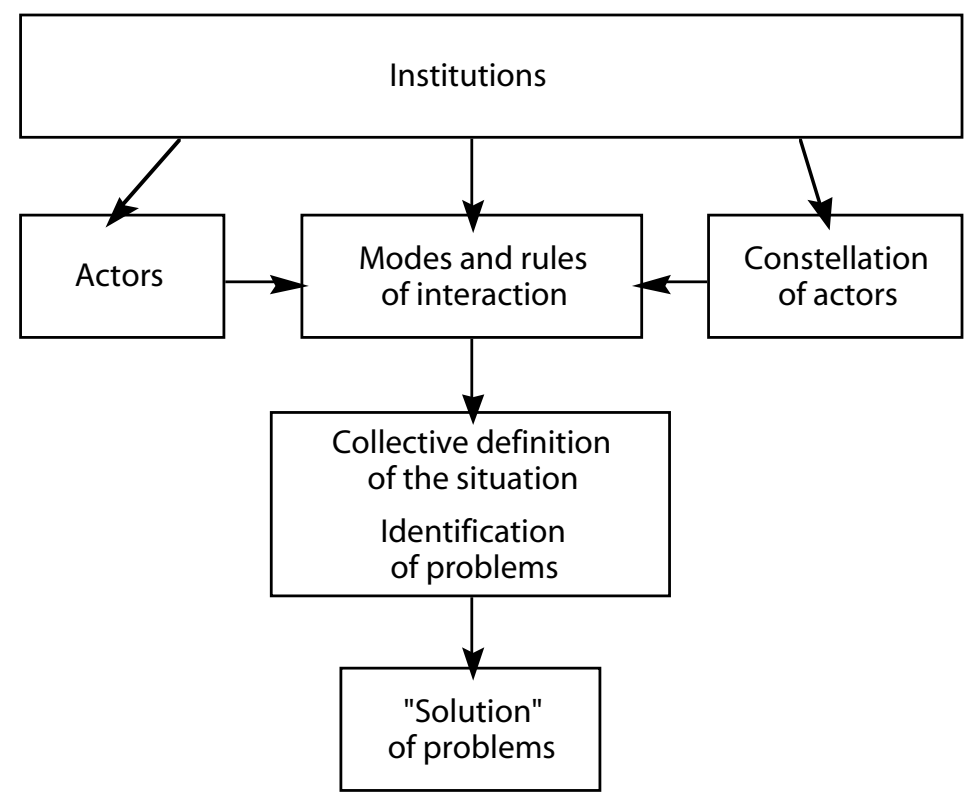


only formal legal rules that are sanctioned by the court system and the machinery of the state, but also social norms that actors will generally respect and whose violation will be sanctioned by loss of reputation, social disapproval, or similar consequences (see also Knight, 1992: 66-73). An organization, as distinct from an institution, can be conceived of as a specific selection, combination, operationalization and structural implementation of these rules. Through organization the rules gain a higher normative obligation because formal and informal internal sanctioning mechanisms become effective.

Institutions as rule systems do not only influence social processes by creating and constraining options, they also in some sense constitute actors - the second module of the ACI approach - and shape their perceptions and preferences. The constructivist elements in this view of actors come to the fore more clearly if we consider the distinction that ACI draws with respect to this module. One category of actors includes individual actors who are assigned roles and competencies through generalized expectations and rules. However, ACI also regards other units than individuals as actors. These units are composite actors, i.e., collective and corporate actors such as business firms, government ministries and agencies, associations or social movements. In the analysis of technical development we often deal with these composite actors, represented by one or many individuals, rather than with individuals acting on their own account. The composite actors are institutionally constituted: they were created according to pre-existing rules, and they depend on rules for their continuing existence and operation. In general, these rules not only define the actors' constituency and the material and legal action resources they can rely on, but also the purposes which they are to serve or the values that they are to consider in arriving at their choices. Individuals acting on behalf of a composite actor will evaluate the outcomes of choices according to the principles and values of the corporate or collective actor. Through constituting corporate and collective action and channeling individual action, institutions as systems of rules make social behavior understandable - and in a limited sense - also predictable for those sharing rule knowledge (Burns, 1985: 256).

In ACI's view, however, actors do not appear as determined by institutions. Institutions only define a scope of acceptable action leaving room for diversity of strategy and choice. They do not simply reduce actors to instruments or marionettes. Individual actors acting as representatives, delegates or agents on behalf of a corporate or collective actor or just on their own account, have different social backgrounds, socialization histories, knowledge, experience and views of the world and therefore must be regarded as enjoying a considerably high degree of autonomy. What from an institutional perspective may be regarded as idiosyncratic in fact constitutes a significant element of social interaction. The dynamics of interaction processes result from both the actors' heterogeneity and relative autonomy as well as the institutional opportunities and constraints which frame a situation. Most institutional approaches, especially those rooted in economics and law, put less emphasis than ACI on the autonomous role of human agency. If institu- 
tionalists take actors - individual and collective - into account they tend to be open to constructivist thinking. An example is provided by a sociological analysis of "the social construction of the early electricity industry in America" in which soft constructivism combining agency and (institutional) structure is used to explain the evolution of this industry as a result of "individual and collective action ... within sharply defined historical and structural constraints" (McGuire et al. 1993, 215).

A third crucial module of actor-centered institutionalism is the constellation of actors, which can be more or less heterogeneous. As ACI predominantly aims at explaining the outcome of interaction and of decision processes it is the mode of interaction and the strategic interdependence of actors in a given constellation that must be scrutinized. The actor-process dynamics which unfold in these constellations significantly affect the outcome. Institutional variables play a crucial role with respect to actor constellations because they shape these constellations and to a certain degree they also define the rules of the interaction processes (rules of the game). In a given constellation of actors a collective definition of the situation emerges which includes identifying or naming of problems and developing concomitant strategies to deal with these problems. Collective actions are directed towards a "solution" of the problems.

\section{Illustrations from the Area of Technical Standardization}

The following examples draw on the process of organized international stan- dardization in telecommunications and information technology with a focus on compatibility standards (e.g. interface standards). They illustrate the ACI approach and at the same time can be used to discuss some crucial concepts of the SCOT approach from the point of view of ACI. Standard setting is a significant step in the process of technical development. Standards serve as a medium to coordinate this development. They are elements of technical knowledge (and not products) and specify relational properties of technical artifacts - often in relation to architectural models of technical systems. As "hardened" officially codified knowledge, standards entail an expectation to comply. In this function the technical rules coordinate human action concerning the design, production, combination, maintenance or utilization of technical artifacts. The standards are addressed to actors, and a selection of these actors sets the rules in standardization processes.

\section{A General Model of Standard-Setting}

Standardization as a committee process of negotiating technical options proceeds slowly. Some elements of a standard are finalized early, others are submitted for further study and discussion. Proposed options are approved or rejected. Experts are mobilized and coalitions are forged in order to strengthen a specific position vis-à-vis competing alternatives. At the end - typically, but not inevitably - a set of technical rules results which is called a standard. From this point of view, the standard is the dependent variable, whose elements and options are influenced by social fac- 
tors such as institutional rules, political and commercial interests, scientific reasoning and other considerations.

The following general model of standard-setting (Diagram 2) has been developed in a more encompassing research project on technical standardization and coordination (Schmidt \&Werle, 1998). It starts out with a distinction of structural aspects and process aspects of standardization. The structural elements (three groups of variables) frame the process of negotiation and decision-making on standards. The second block of variables, called process aspects of standardization, is shaped but not determined by the structural elements. Standardization processes always generate their own dynamics and do not only intervene between the structural elements and the output of the standardization process.
The output as the dependent variable comprises certain features of standards.

\section{Institution}

From the point of view of ACI a more detailed look at the set of structural variables has to start with the institutional framework. ${ }^{2}$ This framework is a system of formal and informal rules concerning among others membership, working procedures and decision-making. With respect to central elements of this rule system many international standardization organizations display substantial similarity but also some specific differences which account for some variation in the output of the standardization process. If we take, for instance, the membership rules we will find that many organizations are quite open to new mem-

Diagram 2. General Model of Standardization

\section{Structural aspects}

\begin{tabular}{l} 
Institutional framework \\
- rules of participation \\
- working levels \\
- procedural rules \\
- decision rules \\
- relation to other \\
standards organizations \\
\hline
\end{tabular}

\section{Actor}

- interests

- recourses

- perceptions

- motives

Technological foundation

- physical feasibility

- stock of technical

knowledge

- dominant designs

- technically determined problems 
bers (all who are substantially interested) but that membership is restricted to organizations rather than individuals. Informal differences in membership rules in combination with fees being charged to the members account for different membership structures and as a result for different standards. To give an example: In the case of standardization of electronic mail systems both the International Telecommunications Union (ITU) and the International Standardization Organization (ISO) adopted a stan dard in 1988. Most features of the standard were identical, but there were differences concerning the distinction of types of e-mail domains and the organization of international e-mail traffic (see Schmidt \& Werle, 1998). These differences can be explained if we consider that Postal and Telecommunications Administrations (PTTs), most of whom in the 1980s still enjoyed national monopoly positions, represented the majority of members of the ITU whereas in the ISO computer manufacturers, software firms and university institutes predominated. Thus, in e-mail standardization the structure of the membership of the organizations issuing the standards account for the differences in the output. The structure of membership can be attributed to the membership rules, which in the case of the ITU denied nonPTTs full membership status.

Including institutional factors such as formal and informal membership rules in the analysis would help social constructivism to deal successfully with some methodological and theoretical problems it has encountered. Take for example the concept of "relevant social groups" and the problem how such groups can be identified. Relevant social groups are those groups which have a significant influence in the social process of "constructing" technical artifacts. The SCOT approach tends to trace these groups on the basis of ex post significance. Starting from the specific technical artifact (the result of the process), those groups are declared as relevant which have been more or less directly involved in the process of construction. Without additional theoretical assumptions this strategy of identifying relevant groups is almost tautological. It risks neglecting, for instance, the meso-level factors which, independently of specific construction processes, distribute opportunities and resources of individuals and groups to shape technology, i.e., to become relevant (or not) in the sense of the SCOT approach. Standardization organizations provide these opportunities. Through their membership rules and other institutional mechanisms they influence the potential relevance of groups. They also constitute groups from actors who were not linked to one another before they joined a standardization organization. Thus starting with a look at institutional settings rather than technical artifacts helps identifying relevant groups in a methodologically valid way.

It may also help assessing the relevance of single members of relevant groups as the example of standardization also demonstrates. Standard-setting is shaped by decision rules which - as a rule - level the playing field. In most organizations decisions on standards are taken according to the one-memberone-vote (or sometimes one-nationone-vote) rule which means that the influence of participants in the voting procedure is not biased by the resources 
they manage. The consensus principle which prevails in many standardization organizations, even if they formally could apply majority voting, grants members veto power who otherwise might be in a marginal position in standardization. Taken together these rules and principles make it possible to analyze and model negotiation processes in standardization and depending on the preferences of the researcher even use the tool kit of institutionally informed game theory (cf. Farrell \& Saloner, 1988; Scharpf, 1993; Schmidt \& Werle, 1994; 1998).

Considering rules and processes of decision-making in organizations also provides an example of how two other concepts which are central to the SCOT approach can be specified from an institutional perspective. The respective concepts are those of "closure" and "stabilization”. Bijker (1995a) uses the concept of "closure" to indicate that the meaning of a technical artifact has been consolidated in a common understanding. Closure in this sense means more than effective termination of a controversy. It "has come to mean the process by which facts or artifacts in a provisional state characterized by controversy are molded in a stable state characterized by consensus" (Misa, 1992: 109). Standardization organizations - our focus - provide arenas in which committees negotiate standards. The negotiations are governed by institutional rules which determine the decision process (sometimes also the legitimacy of arguments) and the value of consensus (cf. Schmidt \& Werle, 1993). Depending on the specific rules, controversies are processed differently, and different forms of closure will prevail. More often than not the process of closure may simply be a formal termination of a controversy, for instance through majority voting, rather than a commonly accepted result. Thus in an institutionalized context closure can be achieved without the actors' convergence on a common meaning of what would be the best or most appropriate standard.

From this point of view it does not only make sense, but appears necessary, to distinguish closure from what Bijker calls "stabilization". Stabilization indicates that an artifact has reached a degree of obduracy at the material level that may affect future technological change. Stabilized artifacts can channel change in a certain direction (trajectory). In organized standardization, stabilization is a process which can only partly be controlled by those who decide upon a standard. The chances of what we call the implementation of a committee standard, i.e., coping generally with the technical rule, will often be enhanced by the formal legitimacy and broad membership of the issuing institution - in particular if according to the prevailing principle consensus has been reachedbut it is not at all guaranteed by these factors. Therefore the social and market processes outside the standardization organizations have be taken into consideration. Eventually the interplay of these forces accounts for the emergence of stability or instability of a standard. However, most standardization organizations regard as a central goal providing for a continuous (stabilized) development of standards; their committees hesitate to radically alter technical rules which have been approved in earlier periods of work. In this sense they channel standardization in a certain direction. 
These examples have demonstrated that looking at the institutional setting in which actors act helps identifying relevant social groups and specifying mechanisms of closure and stabilization in the process of shaping technology, in our case technical standards. We looked at decision rules and membership rules in standardization organizations.

\section{Actors}

The organizations' membership rules influence the recruitment of actors who become involved in the standardization process. But actors will also at times choose the organization within which they prefer to push a standard, weighing the specific institutional opportunities and constraints each standardization organization provides from their point of view. This indicates that another group of structural elements of standardization, the properties of the actors involved, their interests, resources, perceptions and motives, also play a significant role in explaining the outcome. Actors in standardization are in principle organizations which actor centered institutionalism regards as units capable of concerted action (cf. Coleman, 1990: 325-370, 421-450; also Vanberg, 1992). The individual actors are usually delegates of these organizations whose interests they are supposed to represent.

Usually standardization is charged to highly specialized experts, and the delegating organization generally does not have the necessary knowledge to assess the relevance of participation, or to control and monitor the behavior of its own particular delegate. For the individual members, participation might represent some sort of fringe benefit, one with at least potential usefulness for the organization. In a concrete situation it is often difficult to detect if a person acts as an agent of an organization or from personal interest. In short, individual interests may be only loosely connected to discernible corporate actors' interests in certain standards, or to technological developments in general. The methodological issues posed by the distinction of individual and corporate actors in ACI cannot be discussed at this point. They, however, are typical for the kind of problems one encounters if two levels of analysis (micro and meso in this case) shall be linked to one another (cf. Hannan, 1992; Werle, 1995).

Actors approach technical artifacts with their specific rationality. Their perspectives are heterogeneous, and consequently the actors differ in how they conceive of artifacts, their functionality, safety, performance, design and also their status in a technical system and the resulting compatibility and standardization requirements. Partly independent from the institutional setting, actors' perceptions, interests, resources etc. account for the strategies they choose. If we try to relate this premise to constructivist concepts, we can infer that heterogeneity of perspectives relates to what Pinch and Bijker call "interpretative flexibility" (Pinch \& Bijker, 1984; Bijker, 1995a). Different images of a technical artifact co-exist and compete for some time. This suggests flexibility of interpretation in early stages of technical development. Institutional embeddedness shapes and usually reduces flexibility. In standard-setting processes, for instance, a limited set of feasible options is processed: not just anything goes. 


\section{Process}

With the emphasis on heterogeneity ACI always has a constellation of actors, including their interests, perceptions or preferences, in mind. It is in fact the constellation, another crucial module of this approach, which can be more or less heterogeneous. As ACI predominantly aims at explaining the outcome of interaction and of decision processes it is the mode of interaction and the strategic interdependence of actors in a given constellation that ACI focuses on. The actor-process dynamics which unfold in these constellations significantly affect the outcome. All these elements belong to a set of variables which - in our model we call process aspects of standardization. Also here institutional variables have to be considered because they shape actor constellations (e.g. through membership rules) and the rules of the game in negotiations (Scharpf, 1997). They at the same time frame interaction processes and the collective definition of the situation. Institutional frames encompass informal rules specifying legitimate and illegitimate types of reasoning in controversial debates on standards.Our concept of frame borrowed from the psychology of choice indicates that variations in the perception of an "identical" issue are controlled by the formulation of the problem, by norms and habits, and also by the personal characteristics of the decision-maker (Tversky \& Kahneman, 1985; 1988; also Lindenberg, 1993). Changing perceptions can lead to changing preferences and choices, though without affecting the basic individual characteristics of the actors. If we take the circle of actors and their personal characteristics as given, it is mainly the formulation of the problem and the (organizational) norms which cause a differentia specifica of standards development, be it between standardization processes outside and inside standardization organizations, or be it between different standardization organizations such as the ITU and the ISO.

ACI's concept of "frames" and also that of actor constellations, the latter under the slightly different designation of “configurations", are also encountered in constructivist theories. In the SCOT approach a (technological) frame "structures the interactions between the actors of a relevant social group. ... It is built up when interaction 'around' a technology starts and continues" (Bijker, 1995b: 252). The frame attributes meaning to a technical artifact. This comes very close to the ACI's understanding of frames, which highlights their institutional roots. In general constructivists seem to be less concerned than institutionalists with the question where the frames come from and how they are stabilized and reinforced.

As with the concept of frame, the constructivist notion of configuration parallels our use of the concept of constellation. Bijker distinguishes three initial configurations (group constellations) according to the dominance of technological frames which guide interaction. If exactly one group dominates a configuration, one dominant technological frame will guide the interaction. Without a dominant group no frame comes to dominate. Most interesting from the institutionalist perspective is Bijker's example with more than one dominant or powerful group existing. In this case technological frames compete, 
and "external criteria", Bijker argues, may become important (Bijker, 1995a: 277). These external criteria, we suggest, can be found at the meso level of society. Institutions (as meso level phenomena) supply criteria to evaluate different positions, and they provide rules governing interaction which are implemented and operationalized in organizations. Institutions can level power differentials, channel controversies and maybe even homogenize divergent technological frames prevailing in heterogeneous constellations (configurations) of actors.

Not surprisingly from the ACI perspective, institutions do not guarantee the emergence of a common frame. If groups of actors have strongly committed themselves to a specific perspective which may be rooted in a traditional understanding of a phenomenon they may refuse to converge towards the understanding of another group even if there is an institutional expectation to do so. An example is provided by a conflict over a common standard in the area of facsimile transmission in telecommunications. The conflict emerged within the confines of the ITU in a specific standardization committee (Study Group VIII). Two competing standards proposals relying on different images of system architectures caused a struggle that ended in a deadlock. One group of the committee argued in favor of a new standard that should provide for faster and better quality of transmission of documents on the basis of the well established existing standard for analogue telephone networks ("Group 3"-standard). This standard had evolved as a means to pragmatically optimize the use of the traditionally grown telephone network for facsimile purposes, and the new standard would more or less be an upgraded version of the existing one. Another group opted for a standard that would be able to exploit the opportunities of the future fully digitized telecommunications system which they regarded as a data communication system that would integrate voice rather than a telephone system. For such a network a set of standards as part of a principled new systems architecture had already been approved ex ante (standards for the Integrated Services Digital Network ISDN). These standards included a facsimile standard ("Group 4"-standard). However, even the proponents of ISDN conceded that "Group 4" was very complicated and needed streamlining. But they did not want to accept a standard of the "Group 3" type which in their view would retard or even impede the transition to the new telecommunications system. Both sides emphasized the merits of their (principled vs. pragmatic) proposals but they did (or could) not agree on a common set of criteria, a common frame, to evaluate the different features of the proposals. On the other hand, they did not grow tired invoking institutional norms of the ITU, such as the value of consensus, the importance of having only one single standard instead of competing solutions and the need to collectively control the future development of the system of technical communication. But consensus could not be reached and in the end two incompatible standards were adopted and neither has been implemented in telecommunications systems yet.

\section{Conclusion}

Constructivist and institutionalist ap- 
proaches in science and technology are often seen as competing incompatible threads of theorizing. If have tried to show that the gap between the two approaches can be bridged, if we restrict our undertaking to the less radical variants on both sides. This is facilitated by the actor-centered institutional approach which integrates the micro and the meso level of analysis. Social constructivism - in the first place the SCOT approach - with its central focus on the micro level benefits from actor-centered institutionalism because ACI's institutional component focusing on rules and rule systems provides tools to specify crucial concepts of SCOT and to understand how individual action is institutionally shaped. ACI on the other hand also benefits from SCOT. As SCOT provides a substantial understanding of technology from the point of view of the individual actors, interpretations concerning the micro level or the actor component of ACI will be enriched if they integrate elements of SCOT in order to explain technological development.

Such a substantial understanding which can be gained if we follow the actors (Latour, 1987) through science, technology and society often falls short from providing an explanation why specific groups of actors and no others are the relevant actors to follow, why they assess the feasibility of different technical options differently and how they can manage to shape preferences and evaluations of other actors. It is not historical accident that the features of standards approved by committees of traditional standardization organizations are different from those adopted by committees of more exclusive consortia and forums of firms and again different from de- facto standards emerging in markets through "imposition" of a dominant firm or through "pure evolution”. Such differences may be crucial concerning the standards' capability coordinating and guiding action of those who produce or use technology and thereby safeguarding interoperation of single components in encompassing technical systems. Without considering the institutional settings in which actors act and - if possible - comparing such settings we run the risk attributing the outcome of social processes exclusively - and inadequately - to individual actors although the settings account for much of the variation.

Institutionalism has often been criticized as being either too legalistic or too rationalistic. The formal legal perspective tends to treat only legal rules and constitutions as institutions and at the same time blends their normative and empirical validity. The rationalistic approach conceives of institutions as mechanisms of efficient social ordering. From this economic angle, specific existing institutions have emerged as an efficient variant from a set of potential alternatives and they secure efficient social and economic action. Sociological institutionalism has done away with these biases (Hall \& Taylor, 1998; DiMaggio \& Powell, 1983). Its concept of institutions includes legal rules but also other kinds of formal and informal rules such as routines or collective expectations and symbol systems which frame and give meaning to action. Also technical standards can develop into elements of an institutional setting after they have been adopted and implemented. Standardization, in this sense, is an aspect of institution building. The 
empirical study of standard-setting provides evidence that standards often emerge as compromises among technical experts, business managers and also politicians. Rational efficiency neither accounts for their adoption nor for their coordinating effects. This only underlines the position of sociological institutionalism that efficiency is not the prevailing force shaping the emergence and the repercussions of institutions. Social constructivists should have no problem sharing this view.

\section{Notes}

1 The argument draws on Schmidt \&Werle, 1998, where the empirical cases are presented in more detail and a general institutional explanation of the development of standards as rules which are meant to coordinate technical development is suggested.

2 The block with the indicators concerning the technological foundation of the standardization process shall be skipped in this article because this type of variables does not directly fit into the approach of actor-centered institutionalism. This, however, does not mean that the technical variables cannot be integrated into this approach.

\section{References}

Arthur, Brian W.

1989 "Competing Technologies, Increasing Returns, and Lock-In by Historical Events." The Economic Journal 99: 116131.

Bijker, Wiebe E.

1995a Of Bicycles, Bakelites, and Bulbs. Toward a Theory of Sociotechnical Change. Cambridge, MA: MIT.

1995b "Sociohistorical Technology Studies." Pp. 229-256 in Jasanoff et al. (eds.), Handbook of Science and Technology Studies. London: Sage.

Bowden, Gary

1995 "Coming of Age in STS. Some Methodological Musings.” Pp. 64-79 in Jasanoff et al. (eds.), Handbook of Science and Technology Studies. London: Sage.

Braczyk, Hans-Joachim, Cook, Philip and Heidenreich, Martin (eds.)

1998 Regional Innovation Systems. The Role of Governance in a Globalized World. London: UCL Press.

Burns, Tom R.

1985 "Actors, Rule Systems, Social Action: Rule System Analysis for the Social Sciences." Pp. 256-329 in Burns, Baumgartner, Deville (eds.), Man, Decisions, Society. New York: Gordon and Breach Science Publishers.

Callon, Michel

1987 "Society in the Making: The Study of Technology as a Tool for Sociological Analysis." Pp. 83-103 in Bijker, Hughes, Pinch (eds.), The Social Construction of Technological Systems. Cambridge, MA: MIT.

Coleman, James S.

1990 Foundations of Social Theory. Cambridge, MA: Belknap.

Collins, Harry M. and Yearley, Steven

1992 “Epistomological Chicken.” Pp. 301-326 in Pickering (ed.), Science as Practice and Culture. Chicago: University of Chicago Press.

DiMaggio, Paul J. and Powell, Walter W.

1983 “The Iron Cage Revisited: Institutional Isomorphism and Collective Rationality in Organizational Fields." American Sociological Review 48: 147-160.

Edwards, Paul N.

1996 The Closed World. Computers and the Politics of Discourse in Cold War America. Cambridge, MA: MIT Press.

Etzkowitz, Henry and Leydesdorff, Loet (eds.) 1997 Universities and the Global Knowledge Economy. A Triple Helix of University Industry-Government Relations. London/ Washington: Pinter.

Farell, Joseph and Saloner, Garth

1988 "Coordination Through Committees and Markets." Rand Journal of Economics 19: 235-252.

Hall, Peter A. and Taylor, Rosemary C.R.

1998 "Political Science and the Three New Institutionalisms.” Pp. 15-44 in Soltan, Uslaner, Haufler (eds.), Institutions and Social Order. Ann Arbor, Mich.: University of Michigan Press. 
Hannan, Michael T.

1992 "Rationality and Robustness in Multilevel Systems." Pp. 120-136 in Coleman, Fararo (eds.), Rational Choice Theory. Advocacy and Critique. Newbury Park: Sage.

Hughes, Thomas P.

1986 "The Seamless Web: Technology, Science, Etcetera, Etcetera." Social Studies of Science 16: 281-292.

Knight, Jack

1992 Institutions and Social Conflict. Cambridge, MA: Cambridge University Press.

Latour, Bruno

1987 Science in Action. How to Follow Scientists and Engineers through Society. Cambridge, MA: Harvard University Press.

1992 "Where Are the Missing Masses? The Sociology of a Few Mundane Artifacts." Pp. 225-258 in Bijker, Law (eds.), Shaping Technology/ Building Society. Cambridge, MA: MIT.

Law, John and Callon, Michel

1992 "The Life and Death of an Aircraft: A Network Analysis of Technical Change." Pp. 21-52 in Bijker, Law (eds.), Shaping Technology/ Building Society. Studies in Sociotechnical Change. Cambridge, MA: MIT.

Lindenberg, Siegwart

1993 "Framing, Empirical Evidence, and Applications." Pp. 11-38 in HerderDorneich, Schenk, Schmidtchen (eds.), Jahrbuch für Neue Politische Ökonomie. Band 12: Neue Politische Ökonomie von Normen und Institutionen. (Yearbook for New Political Economy, Vol 12: New Political Economy of Norms and Institutions) Tübingen: Mohr.

MacKenzie, Donald

1990 Inventing Accuracy. A Historical Sociology of Nuclear Missile Guidance. Cambridge, MA: MIT.

MacKenzie, Donald and Wajcman, Judy (eds.)

1985 The Social Shaping of Technology. Milton Keynes: Open University Press. Mayntz, Renate and Scharpf, Fritz W.

1995 "Der Ansatz des akteurzentrierten Institutionalismus." (The Approach of
Actor-Centered-Institutionalism) Pp. 39-72 in Mayntz, Scharpf (eds.), Gesellschaftliche Selbstregelung und politische Steuerung. (Social Self-Regulation and Political Governance) Frankfurt a.M.: Campus.

McGuire, Patrick, Granovetter, Mark and Schwartz, Michael

1993 "Thomas Edison and the Social Construction of the Early Electricity Industry in America." Pp. 213-246 in Swedberg (ed.), Explorations in Economic Sociology. New York: Russell Sage Foundation.

Misa, Thomas J.

1992 "Controversy and Closure in Technological Change: Constructing "Steel"." Pp. 109-139 in Bijker, Law (eds.), Shaping Technology/ Building Society Studies in Sociotechnological Change. Cambridge, MA: MIT.

1994 "Retrieving Sociotechnical Change from Technological Determinism." Pp. 115141 in Smith, Marx (eds.), Does Technology Drive History? The Dilemma of Technological Determinism. Cambridge, MA: MIT.

Nelson, Richard R. and Rosenberg, Nathan (eds.)

1993 National Innovation Systems. A Comparative Analysis. Oxford: Oxford University Press.

Nelson, Richard R. and Winter, Sidney G.

1977 "In Search of Useful Theory of Innovation." Research Policy 6: 36-76.

1982 An Evolutionary Theory of Economic Change. Cambridge MA: Belknap Press.

Norberg, Arthur L. and O'Neill, Judy E.

1996 Transforming Computer Technology. Information Processing for the Pentagon, 1962-1986. Baltimore/ London: The Johns Hopkins University Press.

Pinch, Trevor J. and Bijker, Wiebe E.

1984 "The Social Construction of Facts and Artefacts: or How the Sociology of Science and the Sociology of Technology Might Benefit Each Other." Social Studies of Science 14: 399-441.

Scharpf, Fritz W. (ed.)

1993 Games in Hierarchies and Networks. Analytical and Empirical Approaches to the Study of Governance Institutions. Frankfurt a.M./ Boulder, CO: Campus/ Westview. 
Scharpf, Fritz W.

1997 Games Real Actors Play. Actor-Centered Institutionalism in Policy Research. Boulder, CO: Westview.

Schmidt, Susanne K. and Werle, Raymund

1993 Technical Controversy in International Standardization. MPIFG Discussion Paper 93/5. Köln: MPI für Gesellschaftsforschung.

1994 "Die Entwicklung von Kompatibilitätsstandards in der Telekommunikation." (The Development of Compatibility Standards in Telecommunications) Homo oeconomicus 11, 3: 419448.

1998: Coordinating Technology. Studies in the International Standardization of Telecommunications, Cambridge, MA: MIT.

Smit, Wim A.

1995 "Science, Technology, and the Military. Relations in Transition." Pp. 598-626 in Jasanoff et al. (eds.), Handbook of Science and Technology Studies. London: Sage.

Sørensen, Knut H.and Levold, Nora

1992 "Tacit Networks, Heterogenous Engineers, and Embodied Technology." Science, Technology \& Human Values 17, 1: 13-35.

Tversky, Amos and Kahneman, Daniel

1985 "The Framing of Decisions and the Psychology of Choice." Pp. 25-41 in Wright (ed.), Behavioral Decision Making. New York: Plenum.

1988 "Rational Choice and the Framing of Decisions." Pp. 167-192 in Bell, Raiffa, Tversky (eds.), Decision Making. Descriptive, Normative, and Prescriptive Interactions. Cambridge, MA: Cambridge University Press.

Vanberg, Viktor J.

1992 "Organizations as Constitutional Systems." Constitutional Political Economy 3: 223-253.

Vincenti, Walter G.

1995 "The Technical Shaping of Technology: Real-World Constraints and Technical Logic in Edison's Electrical Lighting System." Social Studies of Science 25: 553-574.
Werle, Raymund

1995 "Rational Choice und rationale Technikentwicklung. Einige Dilemmata der Technikkoordination." (Rational Choice and Rational Development of Technology. Some Dilemmas of Coordination of Technology). Pp. 49-76 in Halfmann, Bechmann, Rammert (eds.), Technik und Gesellschaft. Jahrbuch 8: Theoriebausteine der Techniksoziologie. (Technology and Society. YearbookVol. 8: Theory Modules of the Sociology of Technology) Frankfurt a.M.: Campus.

1997 "Academic-Industry-Government Relations and Cross-Sectoral Coordination in the Development of Research and Education Networks (REN).” Pp. 401408 in Enslow, Desrochers, Bonifacio (eds.), 21st Century Communications Networks. Proceedings of the Global Networking '97 Conference (Calgary, Alberta, June 15 to 18, 1997). Vol. II: Policy, Social Applications. Amsterdam: IOS Press.

Winner, Langdon

1993 "Upon Opening the Black Box and Finding It Empty: Social Constructivism and the Philosophy of Technology." Science, Technology \& Human Values 18, 3: 362378.

Woolgar, Steve

1987 "Reconstructing Man and Machine: A Note on Sociological Critiques of Cognitivism.” Pp. 311-328 in Bijker, Hughes, and Pinch (eds.), The Social Construction of Technological Systems. New Directions in the Sociology and History of Technology. Cambridge, MA: MIT.

1991"The Turn to Technology in Social Studies of Science." Science, Technology \& Human Values 16, 1: 20-50.

\section{Raymund Werle \\ Max Planck Institute for the Study of Societies Cologne, Germany}

